\title{
CMEARTICLE
}

\section{Paediatric traumatic brain injury: an approach in primary care}

Haresh $\underline{\text { Singaraju }}^{1}$, MBBS, Adriel Zhijie $\underline{\text { Leong }}^{2}$, MRCS, MPH, Yang Chern $\underline{\text { Lim }}^{3}$, MRCPCH, FAMs, Vincent $\underline{\text { Nga }}^{2}$, MRCSE, FRCSE, Lee Gan Goh${ }^{1}$, MMed, FCFP

Sam, a nine-month-old infant with no significant past medical history, was brought into your clinic by his mother. She had heard a loud thud in the room and found Sam lying prone on the floor and crying. He had likely rolled off the bed, which was 0.7-m high. She attended to him immediately and brought him to your clinic. She appeared extremely worried. No loss of consciousness or seizure-like activity was noted.

\section{WHAT IS TRAUMATIC BRAIN INJURY?}

Traumatic brain injury (TBI) is defined as a disruption in the normal function of the brain that can be caused by a bump, blow, jolt to the head or penetrating head injury. ${ }^{(1)}$

Mild TBI is defined as a Glasgow Coma Scale (GCS) (Table I) score of 13-15, measured at approximately 30 minutes after the injury or, if longer than 30 minutes, at initial presentation. ${ }^{(2,3)}$ Concussion is a subtype of TBI that is caused by a direct blow to the head, face, neck or elsewhere on the body with an impulsive force transmitted to the head, resulting in the rapid onset of short-lived impairment of neurologic function that resolves spontaneously. ${ }^{(4)}$ Impairment of neurologic function may manifest as loss of consciousness, amnesia, confusion or cognitive slowness. ${ }^{(5)}$

\section{HOW RELEVANT IS THIS TO MY PRACTICE?}

$\mathrm{TBI}$ is the most common cause of death or disability in the paediatric population (age 0-16 years). ${ }^{(6)}$ As pivotal brain growth occurs in this population, complications that impede this growth may result in long-term physical, cognitive, socioemotional and financial implications. The disability sustained also has chronic consequences for the family and the community. ${ }^{(7)}$ Fortunately, the majority of TBIs are mild, and disabilities are either absent or transient. As primary care physicians may encounter children with TBI, it is key that they have a clear clinical approach to triaging and managing them.

About half a million visits are made to the paediatric emergency departments per year in the United States for head injury complaints. ${ }^{(8)}$ Locally, KK Women's and Children's Hospital has recorded about 5,000 such visits a year. ${ }^{(9)}$ The majority of paediatric head injuries in Singapore are sustained during falls (with more than half of them occurring at home, mostly involving a high bed and sofa), followed by vehicle accidents, sports, and violence or non-accidental means. ${ }^{(10)}$

The main mechanism of paediatric TBI is dependent on age. ${ }^{(11)}$ Among children aged below two years, non-accidental head injuries (NAIs) and ground-level falls are the most common, whereas falls predominate in children aged $2-4$ years. From age four to teenage years, falls or road traffic accidents (RTAs) are the most common cause of TBI, while in older teenagers, RTAs are the most common cause.

\section{WHAT CAN I DO IN MY PRACTICE? Clinical assessment}

When primary care physicians are faced with managing paediatric head injuries, tapping on their main tools - history and physical examination - is key.

The physician should first identify those who require immediate management at the Children's Emergency. Box 1 shows the clinical assessment sequence used to identify these patients, which is based on various clinical decision rules such as the National Institute for Health and Care Excellence guidelines and the Paediatric Emergency Care Applied Research Network (PECARN) algorithm. ${ }^{(12-15)}$

\section{Clinical guideline tool}

As seen in Box 1, most paediatric TBIs are mild. ${ }^{(11)}$ However, $1 \%$ of these tend to be clinically important TBIs (ciTBI), which are defined as the presence of an intracranial injury on computed tomography (CT) associated with neurosurgical intervention, endotracheal intubation for the management of head injury, and hospitalisation directly related to the head injury for at least 48 hours and/or death. ${ }^{(15)}$

To safely identify children with low risk for ciTBls who do not require neuroimaging, the PECARN algorithm ${ }^{(15)}$ is a wellvalidated paediatric head injury clinical decision rule that primary care physicians can use. It has a sensitivity of $100.0 \%$ and $96.8 \%$ in children below two years of age and those aged two years or older, respectively. Further, it has negative predictive values of $100.00 \%$ and $99.95 \%$, respectively. Although the PECARN algorithm has not been validated in the local context, it has been

${ }^{1}$ Division of Family Medicine, ${ }^{2}$ Division of Neurosurgery, Department of Surgery, ${ }^{3}$ Division of Children's Emergency, Department of Paediatric Medicine, National University Hospital, Singapore

Correspondence: Dr Haresh Singaraju, Chief Resident, Division of Family Medicine, National University Hospital, National University Health System, 1E Kent Ridge Road, Level 9, Singapore 119228. haresh_singaraju@nuhs.edu.sg 
Table I. Paediatric Glasgow Coma Scale (GCS). ${ }^{(25)}$

\begin{tabular}{|c|c|c|c|}
\hline Sign & GCS & $\begin{array}{l}\text { Paediatric GCS } \\
\text { (age }<2 \mathrm{yr} \text { ) }\end{array}$ & Score \\
\hline \multirow{4}{*}{$\begin{array}{l}\text { Eye } \\
\text { opening }\end{array}$} & Spontaneous & Spontaneous & 4 \\
\hline & To voice & To sound & 3 \\
\hline & To pain & To pain & 2 \\
\hline & None & None & 1 \\
\hline \multirow[t]{5}{*}{$\begin{array}{l}\text { Verbal } \\
\text { response }\end{array}$} & Oriented & $\begin{array}{l}\text { Age-appropriate } \\
\text { vocalisation, smile, or } \\
\text { orientation to sound, } \\
\text { interacts (coos, } \\
\text { babbles), follows } \\
\text { objects }\end{array}$ & 5 \\
\hline & Confused & Irritable & 4 \\
\hline & Inappropriate words & Cries to pain & 3 \\
\hline & $\begin{array}{l}\text { Incomprehensible } \\
\text { sounds }\end{array}$ & Moans to pain & 2 \\
\hline & None & None & 1 \\
\hline \multirow[t]{6}{*}{$\begin{array}{l}\text { Motor } \\
\text { response }\end{array}$} & Obeys commands & $\begin{array}{l}\text { Spontaneous or } \\
\text { best achieved by } \\
\text { unaffected limb }\end{array}$ & 6 \\
\hline & Localises pain & $\begin{array}{l}\text { Withdraws to touch } \\
\text { (localises pain) }\end{array}$ & 5 \\
\hline & Withdraws from pain & Withdraws from pain & 4 \\
\hline & $\begin{array}{l}\text { Abnormal flexion } \\
\text { to pain (decorticate } \\
\text { posture) }\end{array}$ & $\begin{array}{l}\text { Abnormal flexion } \\
\text { to pain (decorticate } \\
\text { posture) }\end{array}$ & 3 \\
\hline & $\begin{array}{l}\text { Abnormal extension } \\
\text { to pain (decerebrate } \\
\text { posture) }\end{array}$ & $\begin{array}{l}\text { Abnormal extension } \\
\text { to pain (decerebrate } \\
\text { posture) }\end{array}$ & 2 \\
\hline & None & None & 1 \\
\hline Total & & & 15 \\
\hline
\end{tabular}

validated in various countries, all producing similar results. The algorithm can be accessed online (https://www.mdcalc.com/ pecarn-pediatric-head-injury-trauma-algorithm).

Other tools such as the Canadian Assessment of Tomography for Childhood Head Injury and Children's Head injury ALgorithm for the prediction of Important Clinical Events are widely recognised. The PECARN algorithm was selected because, in comparative studies, its algorithm had the highest sensitivity ${ }^{(16)}$ in identifying patients with TBI who required CT imaging as well as validation, ${ }^{(17)}$ particularly for those with minor head trauma.

\section{Management}

The primary care physician should be able to manage the majority of mild TBIs, since only a minority are ciTBls. Skull radiographs should not be ordered, as they have no role in neuroimaging, except as part of the skeletal survey for non-accidental injury, which is usually conducted in a tertiary hospital.

Based on the PECARN algorithm, physicians who decide to observe their patients need to do so for 4-6 hours. As this would not be practical in the primary care setting, they could decide to either send their patient to the Children's Emergency or back home in the presence of a reliable caregiver, where rest and observation for 24-48
Box 1. Patients who require immediate management at the Children's Emergency:

- Infants aged $<6$ months, as longer observation is required even for a Glasgow Coma Scale (GCS) score of 15(12)

- Red flags on history:

- Inconsistent history from caregiver or mechanism not proportionate to the level of injury observed, a possible indicator of child abuse

- Unknown or dangerous mechanism of injury, including high-speed vehicle accident (e.g. airbags deployed, death or ejection of a fellow passenger, vehicle rollover); not using restraints in a motor vehicle accident; ${ }^{(10)}$ fall from a height > $0.9 \mathrm{~m}$; inflicted trauma; and penetrating injury

- Neurological deficits, including post-traumatic seizures with no history of epilepsy; focal neurological signs; loss of consciousness and/or amnesia for $>5$ minutes (assessment not possible in pre-verbal children and unlikely in any child aged $<5$ years); and more than three vomiting episodes ${ }^{(13)}$

- Abnormal drowsiness (e.g. persistent drowsiness, inability to stay awake despite verbal stimulation)

- More than one concussive episode within a short interval due to the risk of second impact syndrome (permanent neurological injury or death) $)^{(4,14)}$

- Change in behaviour among children aged $<2$ years, according to the caregiver (i.e. not acting normally as per parent)

- On antiplatelet/anticoagulation medication or known bleeding disorder

- Red flags on physical examination

- GCS score, including an initial GCS score $<14$, or for children $<1$ year, GCS (paediatric) < 15; ; $^{(15)}$ or GCS score $<15$ at two hours after an injury

- Head examination: tense fontanelles if age < 18 months; suspected open, depressed and/or palpable skull fracture; signs of base of skull fracture (periorbital ecchymosis - 'Panda's Eyes', Battle's sign, haemotympanum, cerebrospinal fluid otorrhoea and/or rhinorrhoea); non-frontal scalp haematoma, regardless of size

- New focal neurological deficits after injury

- For children aged less than one year, presence of bruise, swelling or laceration of $>5 \mathrm{~cm}$ on the head, regardless of location

- Physician and/or parental preference ${ }^{(15)}$

hours are key. ${ }^{(18)}$ If the latter is chosen, advice on red flags and future injury prevention (e.g. ensuring that younger children are not left alone on high beds or sofas and are instead placed on floor beds or cots, or wearing seat restraints in vehicles and helmets when cycling) must be provided, either in the form of pamphlets or website links (e.g. https://www.cdc.gov/headsup/index.html). These points are to be documented in clinical notes as well. In addition, a follow-up call and scheduled appointment should be arranged. ${ }^{(19)}$ Learning from the COVID-19 situation, telemedicine consultations may also be adopted, as they provide further visual clinical assessment and a sense of reassurance to the physician and the caregiver. ${ }^{(20)}$

Children who sustain concussions should be advised not to return to playing sports or doing physical activity on the same day in order to avoid the risk of second impact syndrome. A strategy 
of gradual return to physical or cognitive activities should be adopted, whereby activities are gradually increased in a stepwise manner as long as the patient remains asymptomatic. ${ }^{(4,5,21)}$ Students returning to school with residual symptoms may benefit from certain accommodations such as being offered a lighter workload and more frequent breaks, and being excused from loud places such as the canteen or assemblies. ${ }^{(5,22)}$ On follow-up, if there are persistent symptoms with inability to resume normal activities within 2-4 weeks, ${ }^{(5)}$ such as post-concussion syndrome (PCS), follow-up with a paediatric neurologist is recommended. Children at risk of PCS include those with a personal history of mood disorders, psychiatric illnesses or migraine. ${ }^{(23)}$

\section{Special consideration - non-accidental injury}

Suspicion of NAI must always be differentially considered by the primary care physician. This is especially so if the history from the informant or caregiver is inconsistent or does not match the degree of injury; or if physical examination reveals poor hygiene, malnutrition, growth restriction, multiple cutaneous bruises of different ages, suspicious pattern injuries, burn marks and skeletal injuries at different stages of healing ${ }^{(24)}$ (although the latter cannot be clinically ascertained in the primary care setting).

If an NAl is suspected, the patient should be referred to the Children's Emergency via ambulance or police escort. In Singapore, police notification must be done. As primary care physicians, we must ensure the safety of the child. The role of primary care physicians in child abuse is to ensure the safety of the at-risk child who cannot protect himself from abuse and to notify the police so that timely investigations can be performed and action can be taken to prevent further harm.

\section{TAKE HOME MESSAGES}

1. Disability from paediatric TBI can pose long-term consequences for the patient, family and society.

2. The severity of paediatric TBI can be identified through a good clinical approach and use of the PECARN clinical guideline tool.

3. NAls should always be differentially considered, especially for younger children.

4. With the help of reliable caregivers and school support, primary care physicians can manage paediatric patients with mild TBI.

Sam was evaluated in the clinic and was eventually consolable. He recognised his name when called, was curious about the clinic setting, sat with a straight back without support and babbled. He had a small haematoma on the frontal scalp but no palpable skull fractures or tense fontanelles. He moved all four limbs well. No other injuries or bruises were noted. Following the PECARN algorithm, computed tomography was not recommended for Sam. This reassured his worried mother. She was given a pamphlet containing advice on red flags for head injury and fall prevention, as well as the clinic number to contact for any enquiries. During the clinical review in two days, Sam was behaving normally and his Glasgow Coma Scale score remained at 15 , with no red flags identified.

\section{REFERENCES}

1. Centers for Disease Control and Prevention. TBI: Get the Facts. Available at: https://www.cdc.gov/traumaticbraininjury/get_the_facts.html. Accessed November 1, 2020.

2. Carroll LJ, Cassidy JD, Holm L, et al. Methodological issues and research recommendations for mild traumatic brain injury: the WHO Collaborating Centre Task Force on Mild Traumatic Brain Injury. J Rehabil Med 2004; (43 Suppl):113-25.

3. Marcin JP, Pollack MM. Triage scoring systems, severity of illness measures, and mortality prediction models in paediatric trauma. Crit Care Med 2002; 30(11 Suppl):S457-67.

4. McCrory P, Meeuwisse W, Dvořák J, et al. Consensus statement on concussion in sport--the $5^{\text {th }}$ international conference on concussion in sport held in Berlin, October 2016. Br J Sports Med 2017; 51:838-47.

5. Silverberg ND, laccarino MA, Panenka WJ, et al. Management of concussion and mild traumatic brain injury: a synthesis of practice guidelines. Arch Phys Med Rehabil 2020; 101:382-93.

6. Araki T, Yokota H, Morita A. Pediatric traumatic brain injury: characteristic features, diagnosis, and management. Neurol Med Chir (Tokyo) 2017; 57:82-93.

7. Bray L. Parents' experiences of hope following a child's brain injury. Nurs Child Young People 2015; 27:22-6.

8. Centers for Disease Control and Prevention. Traumatic Brain Injury in the United States: Emergency Department Visits, Hospitalizations and Deaths 2002-2006. Available at: https://www.cdc.gov/traumaticbraininjury/tbi_ed.html. Accessed January 12, 2021.

9. Lai L. Protect kids from severe injuries. Straits Times 2017 Jun 27. Available at: https://www.straitstimes.com/singapore/protect-kids-from-severe-injuries. Accessed January 12, 2021

10. Chong S, Chew SY, Feng JXY, et al. A prospective surveillance of paediatric head injuries in Singapore: a dual-centre study. BMJ Open 2016; 6:e010618.

11. Kay A, Rodrigues D, Sharp M, Solanki GA. Special considerations in paediatric head and spinal trauma. In: Kirollos R, Helmy A, Thomson S, Hutchinson P, eds. Oxford Textbook of Neurosurgery. Oxford, UK: Oxford University Press, 2019: 999-1008.

12. National University Hospital, Singapore. Approach to apparently minor blunt

head trauma in the children's emergency. 2020 July.

13. National Clinical Guideline Centre (UK). Head injury: Triage, Assessment, Investigation and Early Management of Head Injury in Children, Young People and Adults. NICE Clinical Guidelines No. 176. London, UK: National Institute for Health and Care Excellence, 2014.

14. Halstead ME, Walter KD, Moffatt K, Council on Sports Medicine and Fitness. Sport-related concussion in children and adolescents. Paediatrics 2018; 142:e20183074.

15. Kuppermann N, Holmes JF, Dayan PS, et al. Identification of children at very low risk of clinically-important brain injuries after head trauma: a prospective cohort study. Lancet 2009; 374:1160-70.

16. Babl FE, Borland ML, Phillips N, et al. Accuracy of PECARN, CATCH, and CHALICE head injury decision rules in children: a prospective cohort study. Lancet 2017; 389:2393-402.

17. Mastrangelo M, Midulla F. Minor head trauma in the pediatric emergency department: decision making nodes. Curr Pediatr Rev 2017; 13:92-9.

18. Lumba-Brown A, Yeates KO, Sarmiento K, et al. Centers for Disease Control and Prevention guideline on the diagnosis and management of mild traumatic brain injury among children. JAMA Pediatr 2018; 172:e182853.

19. Davis GA, Purcell L, Schneider KJ, et al. The Child Sport Concussion Assessment Tool $5^{\text {th }}$ Edition (Child SCAT5): background and rationale. Br J Sports Med 2017; 51:859-61.

20. Greenhalgh T, Koh GCH, Car J. Covid-19: a remote assessment in primary care. BMJ 2020; 368:m1182.

21. Almeida AA, Lorincz MT, Hashikawa AN. Recent advances in pediatric concussion and mild traumatic brain injury. Pediatr Clin North Am 2018; 65:1151-66.

22. Iverson GL, Gioia GA. Returning to school following sport-related concussion. Phys Med Rehabil Clin North Am 2016; 27:429-36.

23. Morgan CD, Zuckerman SL, Lee YM, et al. Predictors of postconcussion syndrome after sports-related concussion in young athletes: a matched casecontrol study. J Neurosurg Pediatr 2015; 15:589-98.

24. Kempe $\mathrm{CH}$, Silverman FN, Steele BF, et al. The battered-child syndrome. JAMA $1962 ; 181: 17-24$

25. Holmes JF, Palchak MJ, MacFarlane T, Kuppermann N. Performance of the pediatric Glasgow coma scale in children with blunt head trauma. Acad Emerg Med 2005; 12:814. 


\section{SINGAPORE MEDICAL COUNCIL CATEGORY 3B CME PROGRAMME} (Code SMJ 202109A)

1. Traumatic brain injury (TBI) is defined as a disruption in the normal function of the brain that can be caused by a bump, blow, jolt to the head or penetrating head injury.

2. After malignancy, $\mathrm{TBI}$ is the second most common cause of death and disability in children.

3. Mild TBI is defined as TBI with a Glasgow Coma Scale score of 12-14.

4. Concussion is a type of mild TBI.

5. The most common cause of head injury among teenagers is non-accidental injury.

6. All infants below six months of age with head injury should be referred to the hospital.

7. Falls from the bed or sofa are a common cause of head injury in children aged less than two years.

8. If an 18-month-old child sustains a head injury from a fall off a bed $1 \mathrm{~m}$ in height, he/she should be referred to the hospital.

9. It is a red flag if a caregiver feels that a child is different from his/her norm after a head injury.

10. You notice clear rhinorrhoea in a child with head injury. You should be worried about cerebrospinal fluid rhinorrhoea.

11. A two-year-old presents with a $1 \mathrm{~cm} \times 1 \mathrm{~cm}$ haematoma over the region of his frontal bone. There are no red flags on history or physical examination. You should be concerned.

12. Clinically important TBI is a type of TBI with presence of intracranial injury on computed tomography of the brain.

13. The PECARN algorithm can be easily accessed online and is used to identify children with clinically important TBI.

14. Primary care physicians can manage $99 \%$ of mild TBIs in the paediatric population.

15. Children with mild TBI can be sent home without follow-up.

16. Children with concussion should not return to playing sports on the same day owing to the risk of second impact syndrome.

17. Students returning to school with residual post-concussive symptoms should be given a memo to allow certain accommodations such as less homework or avoiding loud places such as the canteen or assemblies.

18. If post-concussive symptoms have been partially improving but not resolving for about a month, primary care physicians should continue looking after these patients.

19. You are seeing a child with bruises of different ages. Your top suspicion should be non-accidental injury.

20. Skull radiographs can help to determine the extent of a paediatric head injury.

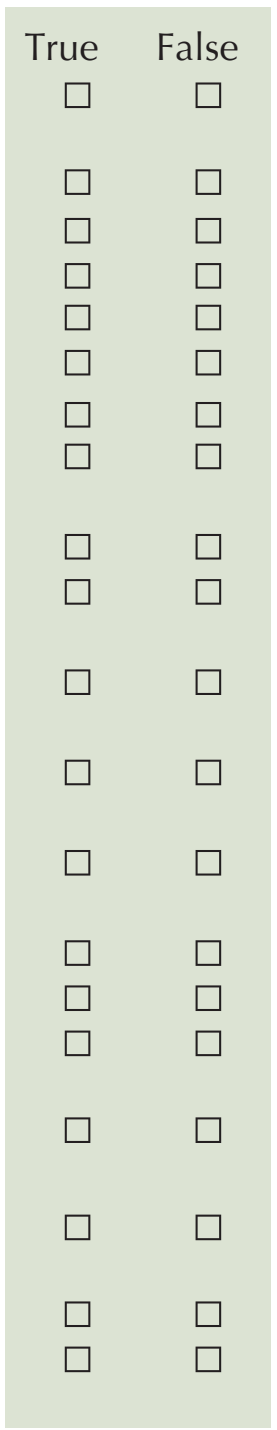

\section{Doctor's particulars:}

Name in full:

MCR no:

Specialty:

Email:

\section{SUBMISSION INSTRUCTIONS:}

Visit the SMJ website: http://www.smj.org.sg/current-issue and select the appropriate quiz. You will be redirected to the SMA login page.

For SMA member: (1) Log in with your username and password (if you do not know your password, please click on 'Forgot your password?'). (2) Select your answers for each quiz and click 'Submit'.

For non-SMA member: (1) Create an SMJ CME account or log in with your SMJ CME username and password (for returning users). (2) Make payment of SGD 21.40 (inclusive of $7 \%$ GST) via PayPal to access this month's quizzes. (3) Select your answers for each quiz and click 'Submit'.

RESULTS:

(1) Answers will be published online in the SMJ November 2021 issue. (2) The MCR numbers of successful candidates will be posted online at the SMJ website by 30 November 2021. (3) Passing mark is $60 \%$. No mark will be deducted for incorrect answers. (4) The SMJ editorial office will submit the list of successful candidates to the Singapore Medical Council. (5) One CME point is awarded for successful candidates. (6) SMC credits CME points according to the month of publication of the CME article (i.e. points awarded for a quiz published in the September 2021 issue will be credited for the month of September 2021, even if the deadline is in November 2021).

Deadline for submission (September 2021 SMJ 3B CME programme): 12 noon, 23 November 2021. 